\title{
An analysis of ranibizumab treatment and visual outcomes in real-world settings: the UNCOVER study
}

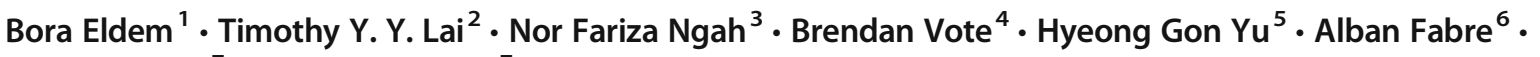 \\ Arthur Backer $^{7} \cdot$ Nathan J. Clunas ${ }^{7}$
}

Received: 31 March 2017 / Revised: 20 December 2017 / Accepted: 27 December 2017 / Published online: 3 March 2018

(C) The Author(s) 2018. This article is an open access publication

\begin{abstract}
Purpose To describe intravitreal ranibizumab treatment frequency, clinical monitoring, and visual outcomes (including mean central retinal thickness [CRT] and visual acuity [VA] changes from baseline) in neovascular age-related macular degeneration (nAMD) in real-world settings across three ranibizumab reimbursement scenarios in the Middle East, North Africa, and the AsiaPacific region.

Methods Non-interventional multicenter historical cohort study of intravitreal ranibizumab use for nAMD in routine clinical practice between April 2010 and April 2013. Eligible patients were diagnosed with nAMD, received at least one intravitreal ranibizumab injection during the study period, and had been observed for a minimum of 1 year (up to 3 years). Reimbursement scenarios were defined as self-paid, partially-reimbursed, and fully-reimbursed.

Results More than three-fourths $(n=2521)$ of the analysis population was partially-reimbursed for ranibizumab, while $16.4 \%$ $(n=532)$ was fully-reimbursed, and 5.8\% was self-paid $(n=188)$. The average annual ranibizumab injection frequency was 4.1 injections in the partially-reimbursed, 4.7 in the fully-reimbursed and 2.6 in the self-paid populations. The average clinical monitoring frequency was estimated to be 6.7 visits/year, with similar frequencies observed across reimbursement categories. On average, patients experienced VA reduction of -0.7 letters and a decrease in CRT of $-44.4 \mu \mathrm{m}$. The greatest mean CRT change was observed in the self-paid group, with $-92.6 \mu \mathrm{m}$.

Conclusions UNCOVER included a large, heterogeneous ranibizumab-treated nAMD population in real-world settings. Patients in all reimbursement scenarios attained vision stability on average, indicating control of disease activity.
\end{abstract}

Keywords Observational study $\cdot$ Ranibizumab $\cdot$ Visual acuity $\cdot$ Tomography $\cdot$ Optical coherence

Electronic supplementary material The online version of this article (https://doi.org/10.1007/s00417-017-3890-8) contains supplementary material, which is available to authorized users.

Bora Eldem

beldem@superonline.com

1 Ophthalmology Department, Hacettepe University School of Medicine, 06100 Ankara, Samanpazarı, Turkey

2 Department of Ophthalmology and Visual Sciences, The Chinese University of Hong Kong, Hong Kong, China

3 Department of Ophthalmology, Hospital Selayang, Selayang Selangor, Malaysia

4 Launceston Eye Institute, South Launceston, Australia

5 Department of Ophthalmology, Seoul National University College of Medicine, Seoul, South Korea

6 IQVIA, Barcelona, Spain

7 Novartis Pharma AG, Basel, Switzerland

\section{Introduction}

Age-related macular degeneration (AMD) causes progressive, severe, irreversible vision loss and is the leading cause of blindness in individuals older than 50 years [1]. The neovascular form of AMD (nAMD) is characterized by choroidal neovascularization. Although nAMD is much less common than other forms of AMD, $80 \%$ to $90 \%$ of severe vision loss related to AMD is attributable to this form [2, 3].

Pooled prevalence estimates from a meta-analysis of Asian populations aged 40 to 79 years in Singapore, Japan, China, Taiwan, Brazil, the United States, and India were $6.8 \%$ for early AMD and $0.56 \%$ for late AMD [4]. Projections by Wong and colleagues suggested that in the year 2040, there will be 113 million cases of any form of AMD in Asia, and 39 million cases each in Africa, Latin America, and the Caribbean [5]. 
Recent literature has also revealed specific subtypes of nAMD such as polypoidal choroidal vasculopathy (PCV) [6] and retinal angiomatous proliferation (RAP). PCV prevalence among patients with nAMD is estimated to be $22 \%$ to $55 \%$ in Asian populations and $4 \%$ to $14 \%$ in Caucasian patients, while the RAP subtype may be present in up to $15 \%$ of all newly diagnosed nAMD cases [7].

Ranibizumab (Lucentis, Novartis Pharma AG, Basel, Switzerland; Genentech Inc., San Francisco, CA, USA), an anti-vascular endothelial growth factor (anti-VEGF) agent specifically designed for ocular use, is licensed for the treatment of nAMD worldwide. The efficacy and safety of monthly intravitreal injections of ranibizumab have been demonstrated in several clinical trials, notably MARINA and ANCHOR $[8,9]$. LUMINOUS, a non-interventional study on safety and effectiveness of ranibizumab, was conducted in Asia, Australia, Europe, and North and South America, and provides further support for its positive safety profile. A retrospective, pooled safety analysis of data from 4 European nAMD registries in the LUMINOUS program exhibited a favorable 1-year safety profile for ranibizumab in routine clinical practice [10].

The recommended regimen of monthly administration schedules of ranibizumab that were used in early clinical trials has proved burdensome to patients and the healthcare system due to factors such as cost of treatment. Subsequent investigations have examined the efficacy of alternative ranibizumab treatment regimens with fewer injections, such as "pro re nata" (PRN) regimen, in which the drug is administered on an as-needed basis, and "treat and extend" (T\&E) regimen, in which the drug is administered on a regular basis until the condition stabilizes; after stabilization, the interval between additional treatments is based on changes in specific clinical parameters [11-14]. The HARBOR clinical trial, wherein patients received 3-month loading doses of ranibizumab followed by PRN regimen, demonstrated clinically meaningful visual improvement at 12 and 24 months from baseline $[15,16]$.

While some publications have demonstrated the efficacy, positive safety profile, and cost-effectiveness associated notably with PRN treatment, to the best of our knowledge, no study has yet examined ranibizumab use and visual outcomes by treatment reimbursement scenarios. The noninterventional UNCOVER (UNraveling nAMD real life Clinical management and Outcome with intraVitrEal Ranibizumab injection) historical cohort study was designed to describe ranibizumab treatment frequency, visual outcomes, and their correlation, in addition to clinical monitoring frequency of patients treated for nAMD in realworld settings in the Middle East, North Africa, and the Asia-Pacific region. Patients included in UNCOVER were categorized by ranibizumab reimbursement scenario (fullyreimbursed, partially-reimbursed, or self-paid).

\section{Material and methods}

UNCOVER was a multicenter historical cohort study of intravitreal ranibizumab use for $\mathrm{nAMD}$ in routine clinical practice based on the abstraction of medical records. Among the 60 ophthalmology centers that participated in this study, three were government hospitals, three were primary care settings, ten were private institutions, and 44 were teaching or university hospitals. Data for nAMD patients were extracted from their medical records in the following ten countries: Algeria, Australia, Hong Kong, India, Malaysia, Saudi Arabia, Singapore, South Korea, Thailand, and Turkey.

The objectives of this study were to describe ranibizumab treatment frequency, pattern of care (i.e., clinical monitoring frequency), and clinical outcomes (including mean central retinal thickness [CRT] and visual acuity [VA] changes from baseline) across three reimbursement scenarios. Those scenarios were defined as fully-reimbursed when the cost of ranibizumab was paid in full by insurance (private, government, etc.), partially-reimbursed when it was paid partially by insurance and the patient, and self-paid when it was paid entirely by the patient. The correlation between the frequency of ranibizumab injections and VA or CRT was also explored.

The study protocol was approved by ethics committees or institutional review boards in each participating country, and by the Ministry of Health in Algeria. Informed consent was obtained from individual participants included in the study where required. A waiver of informed consent was obtained for all sites in Algeria, Malaysia, Singapore, Saudi Arabia and Turkey, and a subset of sites in Hong Kong, India, South Korea, and Thailand.

\section{Study participants}

All patients with a diagnosis of nAMD who received at least one intravitreal ranibizumab injection at any time between April 2010 and April 2013 and had been observed for a minimum of 1 year (up to 3 years) were eligible for this study. The observation period for each patient started with the first ranibizumab injection recorded during the study period (baseline) and ended at either last monitoring of ranibizumab treatment or when the patient switched to another anti-VEGF treatment. Patients were excluded from participation if they received intravitreal bevacizumab or other anti-angiogenic agents intermittently or concomitantly during the study period, or if they received treatment with a ranibizumab dose other than $0.5 \mathrm{mg}$.

\section{Study outcomes}

Patients were characterized by ranibizumab reimbursement scenario, medical history, date of nAMD diagnosis and prior nAMD treatment. Concomitant nAMD therapies (other than 
additional anti-VEGF therapy), adverse events (AEs) as reported in the medical records, and changes in nAMD therapy (including names of therapies and reason for switching) were also collected at the end of the observation period. Dates of administration of $0.5 \mathrm{mg}$ intravitreal injections of ranibizumab (by eye) were collected to assess the frequency of ranibizumab treatment (injections per year), while measurements of VA (in letters) and optical coherence tomography measures of CRT (in $\mu \mathrm{m}$ ) were collected to assess the clinical monitoring frequency and the changes in VA and CRT from baseline. Clinical monitoring frequency was derived from the number of VA and CRT assessments per year.

\section{Statistical analysis}

The final analysis population included all eligible patients. All analyses were stratified by reimbursement scenario. All statistical tests were for exploratory purposes and were 2-sided (alpha $<0.05)$. Continuous variables were described by mean and standard deviation $( \pm$ ). A patient-level analysis (the patient as the analysis unit) was conducted on various characteristics such as age, sex, race, ethnicity, country, relevant medical history/comorbidities, and AEs. An eye-level analysis (the eye as the analysis unit) was also conducted to assess: duration from nAMD diagnosis to first ranibizumab injection reported in the study, nAMD history, ranibizumab treatment and clinical monitoring frequencies, number of VA and CRT assessments, VA and CRT change from baseline. Baseline assessments for VA and CRT were defined as measurements occurring on the day of the first recorded ranibizumab injection, or at any time prior to the first recorded injection during the observation period. The association between changes in VA and CRT from baseline to the last assessment and frequency of ranibizumab injections was examined using the Spearman rank correlation coefficient among the eye-population. A best subsets regression model using R-squared methods was conducted to identify variables associated with changes in VA and CRT from baseline to the last assessment. The eyes of an individual were considered independent given the pathophysiology of nAMD.

Two subgroups were identified for the analyses. Subgroup A: patients with the last recorded ranibizumab injection occurring between 13 and 24 months after the first recorded injection; and subgroup B: patients with the last recorded injection occurring between 25 and 36 months after the first recorded injection. All analyses were performed with the statistical software SAS® (SAS Institute, Cary, NC, USA).

\section{Results}

A total of 3445 eligible patients were enrolled. Among those, 3241 patients meeting all inclusion criteria were included in the final analysis population, corresponding to 3725 treated eyes (overall eye-population).

\section{Baseline characteristics}

Approximately three-quarters of the analysis population $(77.8 \%, n=2521)$ were partially-reimbursed for ranibizumab, $16.4 \%$ were $(n=532)$ fully-reimbursed, and $5.8 \%$ self-paid $(n=188)$ (Table 1). The majority of patients were from Turkey (40.1\%), followed by Australia (27.5\%), and South Korea $(20.4 \%)$. Turkish patients made up the highest proportion $(51.1 \%)$ of the partially-reimbursed group, Australian patients made up the largest proportion $(40.0 \%)$ of the fullyreimbursed group, and Hong Kong patients made up $61.2 \%$ of the self-paid group (Table 1).

The mean observation period was $22.3( \pm 7.83)$ months in the overall population, and was similar across reimbursement categories (Table 2). Gender was similarly distributed among the fully- and partially-reimbursed groups (53.2\% and $50.3 \%$ female respectively), while males comprised the majority of the self-paid group (65.4\% male) (Table 1). Similar age distributions were observed across reimbursement groups, with a mean age of $73.5( \pm 9.98)$ years overall (Table 2$)$. A higher proportion of the self-paid group had eye-related medical history events compared to the two other reimbursement categories, notably PCV (33\% versus approximately 5\%, $n=62$ versus $n=138$ and $n=27$ in the partially- and fully-reimbursed populations respectively) (Table 2$)$.

On average, treated eyes ( $n=3725)$ were diagnosed with nAMD 1 year prior to the observation period start. Half of the eyes were diagnosed with nAMD approximately 1 month prior to the observation period start, irrespective of the reimbursement category (median of 0.1 years). Six hundred and twenty-two eyes $(622,16.7 \%)$ received another nAMD treatment prior to starting ranibizumab. Photodynamic therapy (PDT) was the most common concomitant nAMD treatment in the self-paid group (16.0\%) (Table 3).

\section{Ranibizumab use and monitoring}

Mean yearly ranibizumab injection frequency was $2.6( \pm 1.71)$ in the self-paid category, $4.1( \pm 2.94)$ in the partiallyreimbursed population (mainly driving the overall eyepopulation results), and $4.7( \pm 2.87)$ in the fully-reimbursed population (Fig. 1). The clinical monitoring frequency was approximately 7 visits per year on average in the overall eye-population. Similar figures were observed across the reimbursement categories (Table 4).

\section{Visual outcomes}

Among the overall eye-population, the eyes $(82.4 \%, n=3069)$ with at least two VA assessments had a mean VA change of 
Table 1 Analysis population by country

\begin{tabular}{llllr}
\hline Analysis population, no. (\%) & \multicolumn{2}{l}{ Ranibizumab medical coverage } & $\begin{array}{l}\text { All combined } \\
(n=3241)\end{array}$ \\
\cline { 2 - 4 } & $\begin{array}{l}\text { Fully-reimbursed } \\
(n=532)\end{array}$ & $\begin{array}{l}\text { Partially-reimbursed } \\
(n=2521)\end{array}$ & $\begin{array}{l}\text { Self-paid } \\
(n=188)\end{array}$ & \\
\hline Algeria & $38(7.1 \%)$ & 0 & 0 & $38(1.2 \%)$ \\
Australia & $213(40.0 \%)$ & $671(26.6 \%)$ & $7(3.7 \%)$ & $891(27.5 \%)$ \\
Hong Kong & $31(5.8 \%)$ & $12(0.5 \%)$ & $115(61.2 \%)$ & $158(4.9 \%)$ \\
India & $9(1.7 \%)$ & $4(0.2 \%)$ & $26(13.8 \%)$ & $39(1.2 \%)$ \\
Republic of Korea & $113(21.2 \%)$ & $538(21.3 \%)$ & $9(4.8 \%)$ & $660(20.4 \%)$ \\
Malaysia & $63(11.8 \%)$ & $1(0.0 \%)$ & $22(11.7 \%)$ & $86(2.7 \%)$ \\
Saudi Arabia & $12(2.3 \%)$ & 0 & 0 & $12(0.4 \%)$ \\
Singapore & 0 & $6(0.2 \%)$ & $1(0.5 \%)$ & $7(0.2 \%)$ \\
Thailand & $48(9.0 \%)$ & 0 & $2(1.1 \%)$ & $50(1.5 \%)$ \\
Turkey & $5(0.9 \%)$ & $1289(51.1 \%)$ & $6(3.2 \%)$ & $1300(40.1 \%)$ \\
\hline
\end{tabular}

$-0.7( \pm 22.02)$ letters from baseline. The mean VA change from baseline was lower than 5 letters across the different reimbursement categories (Fig. 2). For $60.4 \%$ of eyes assessed ( $n=1853)$, no VA change $(n=624)$ or a gain of letters was observed ( $n=583$ gained lower than 15 letters and $n=646$ gained 15 letters or greater); whereas $21.4 \%$ of eyes assessed lost 15 letters or more $(n=657)$. Nearly two-thirds $(57.7 \%, n=2148)$ of the overall eye-population had at least two CRT assessments, and a mean CRT change of -44.4
$( \pm 140.69) \mu \mathrm{m}$ was observed from baseline. CRT decreased across all reimbursement categories, with the largest mean decrease observed in the self-paid group $(-92.6[ \pm 196.93]$ $\mu \mathrm{m})$ (Fig. 3).

In the univariate analysis, there was a weak correlation between the mean VA change or CRT change and the frequency of ranibizumab injections over the observation period, with a correlation coefficient of $0.042(P=0.019)$ and $0.010(P=$ $0.757)$ for VA and CRT change respectively.
Table 2 Patient baseline characteristics

\begin{tabular}{lllll}
\hline Patient baseline characteristics & \multicolumn{2}{l}{ Ranibizumab medical coverage } & $\begin{array}{l}\text { All combined } \\
(n=3241)\end{array}$ \\
\cline { 2 - 4 } & $\begin{array}{l}\text { Fully-reimbursed } \\
(n=532)\end{array}$ & $\begin{array}{l}\text { Partially-reimbursed } \\
(n=2521)\end{array}$ & $\begin{array}{l}\text { Self-paid } \\
(n=188)\end{array}$ & \\
\hline $\begin{array}{l}\text { Mean observation period } \\
\text { in months [SD] }\end{array}$ & $23.9[8.24]$ & $22.0[7.79]$ & $21.9[6.57]$ & $22.3[7.83]$ \\
$\begin{array}{l}\text { Mean age in years [SD] } \\
\text { Female, no. (\%) }\end{array}$ & $75.5[10.10]$ & $73.2[9.87]$ & $71.9[10.38]$ & $73.5[9.98]$ \\
Race, no. (\%) & $283(53.2 \%)$ & $1267(50.3 \%)$ & $65(34.6 \%)$ & $1615(49.8 \%)$ \\
$\begin{array}{l}\text { Caucasian } \\
\text { Asian }\end{array}$ & $230(43.2 \%)$ & $1259(49.9 \%)$ & $7(3.7 \%)$ & $1496(46.2 \%)$ \\
$\begin{array}{l}\text { Other } \\
\text { Medical history }\end{array}$ & $264(49.6 \%)$ & $582(23.1 \%)$ & $175(93.1 \%)$ & $1021(31.5 \%)$ \\
$\begin{array}{l}\text { Cataract } \\
\text { Pseudophakia }\end{array}$ & $38(7.1 \%)$ & $678(26.9 \%)$ & $6(3.2 \%)$ & $722(22.3 \%)$ \\
$\begin{array}{l}\text { Polypoidal choroidal } \\
\text { vasculopathy }\end{array}$ & $227(42.7 \%)$ & $822(32.6 \%)$ & $98(52.1 \%)$ & $1147(35.4 \%)$ \\
$\begin{array}{l}\text { Hypertension } \\
\text { Diabetes mellitus }\end{array}$ & $116(21.8 \%)$ & $557(22.1 \%)$ & $66(35.1 \%)$ & $739(22.8 \%)$ \\
$\begin{array}{l}\text { Dyslipidemia } \\
\text { Other cardiovascular } \\
\text { events }\end{array}$ & $27(5.1 \%)$ & $138(5.5 \%)$ & $62(33.0 \%)$ & $227(7.0 \%)$ \\
\hline
\end{tabular}

${ }^{\text {a }}$ Most prevalent medical conditions are presented (representing at least $10 \%$ of one or more reimbursement categories)

$S D$, standard deviation 
Table 3 Eye baseline characteristics

\begin{tabular}{|c|c|c|c|c|}
\hline \multirow[t]{2}{*}{ Eye baseline characteristics } & \multicolumn{3}{|c|}{ Ranibizumab medical coverage } & \multirow{2}{*}{$\begin{array}{l}\text { All combined } \\
(n=3725)\end{array}$} \\
\hline & Fully-reimbursed $(n=580)$ & Partially-reimbursed $(n=2954)$ & Self-paid $(n=200)$ & \\
\hline Right eye, no. (\%) & $304(52.4 \%)$ & $1485(50.4 \%)$ & $99(49.5 \%)$ & $1888(50.7 \%)$ \\
\hline Mean time since diagnosis in years $[\mathrm{SD}]$ & $0.8[1.30]$ & $1.1[2.02]$ & $0.8[1.81]$ & $1.0[1.91]$ \\
\hline Median time since diagnosis in years [IQR] & $0.1[0.0-1.1]$ & $0.1[0.0-1.4]$ & $0.1[0.0-0.8]$ & $0.1[0.0-1.3]$ \\
\hline Treatment received prior to ranibizumab, no. (\%) & $130(22.4 \%)$ & $438(14.9 \%)$ & $54(27.0 \%)$ & $622(16.7 \%)$ \\
\hline Photodynamic therapy & $70(12.1 \%)$ & $133(4.5 \%)$ & $32(16.0 \%)$ & $235(6.3 \%)$ \\
\hline Other anti-VEGF & $65(11.2 \%)$ & $273(9.3 \%)$ & $13(6.5 \%)$ & $351(9.4 \%)$ \\
\hline Other & $14(2.4 \%)$ & $72(2.4 \%)$ & $17(8.5 \%)$ & $103(2.8 \%)$ \\
\hline Surgery & $1(0.2 \%)$ & $40(1.4 \%)$ & $2(1.0 \%)$ & $43(1.2 \%)$ \\
\hline Laser & $11(1.9 \%)$ & $25(0.8 \%)$ & $3(1.5 \%)$ & $39(1.0 \%)$ \\
\hline Steroid & $5(0.9 \%)$ & $8(0.3 \%)$ & $1(0.5 \%)$ & $14(0.4 \%)$ \\
\hline Mean baseline VA in letters [SD] & $61.4[24.18]$ & $62.5[26.83]$ & $57.7[24.99]$ & $62.1[26.38]$ \\
\hline Mean baseline CRT in $\mu \mathrm{m}$ [SD] & $348.7[158.33]$ & $317.1[128.07]$ & $420.1[198.12]$ & $327.6[139.93]$ \\
\hline
\end{tabular}

Anti-VEGF, anti-vascular endothelial growth factor; $C R T$, central retinal thickness; $I Q R$, interquartile range; $S D$, standard deviation; VA, visual acuity

The multivariate regression model showed that, irrespective of the patient profile and length of the observational period, the VAS increased by +0.66 letters per additional ranibizumab injection per year on average $(P<0.001)$ (Online Resource 1$)$. Considering the different reimbursement scenarios, the CRT decreased by $-22.70 \mu \mathrm{m}$ on average in the partiallyreimbursed group $(P=0.007)$, while it decreased by $-40.41 \mu \mathrm{m}$ in the fully-reimbursed group $(P=0.004)$ on average when adjusting to baseline co-variates (Online Resource 2). In addition, the CRT decreased by $-40.50 \mu \mathrm{m}$ among Asian patients $(P<0.001)$ while VA remained stable, with +4.52 letters on average in this group $(P<0.001)$.

\section{Safety data}

Of 3445 patients, 484 (14.0\%) had at least one AE reported in their medical records. Eye disorders were the most common AEs reported $(n=293,8.5 \%)$, followed by general disorders and administration site conditions ( $n=53,1.5 \%)$. Injury, poisoning and procedural complications were reported in $1.5 \%$ of patients $(n=52)$, infections and infestations in $1.5 \%(n=50)$, and nervous system disorders in $1.0 \%(n=36)$.

Eye disorders were more often reported in the self-paid group $(n=46,21.9 \%)$ than in the other groups, notably conjunctival hemorrhage $(n=16,7.6 \%)$, retinal detachment $(n=13$, $6.2 \%)$, and vitreous hemorrhage $(n=8,3.8 \%)$ (Table 5).

\section{Concomitant nAMD therapy and switch to another anti-VEGF}

Of 333 eyes ( $8.9 \%$ overall) with a concomitant nAMD therapy, $58.3 \%(n=194)$ of eyes were treated with PDT, and $47.1 \%$ $(n=157)$ received either laser, steroid, surgery, or other treatment (Table 6).

At the end of the observation period, 341 eyes $(9.2 \%$ overall) were switched to another anti-VEGF treatment, of which $73.3 \%(n=250)$ were switched to bevacizumab and $26.7 \%$ $(n=91)$ to aflibercept (Table 7). A balanced distribution of switches between bevacizumab and aflibercept was observed in the fully-reimbursed group.

Of patients who switched to another anti-VEGF $(n=341)$, the most frequently recorded reason for switching was cost ( $n=135,39.6 \%$ ). The same reason was observed to be the most frequent in the partially-reimbursed group. In the selfpaid group ( $n=11$ switching to another anti-VEGF), patient preference was reported as the reason for switch in $54.5 \%$ of eyes $(n=6)$, and cost in $36.4 \%(n=4)$. In the fully-reimbursed group ( $n=36$ switching to anti-VEGF), efficacy was reported as the main reason for switch for half of the eyes $(n=18)$ (Table 7).

\section{Subgroup results}

There were 1166 patients and 1253 eyes in subgroup A (patients with last ranibizumab injection 13-24 months after first ranibizumab injection, $36.0 \%$ of analysis population). Subgroup B was smaller, with 719 patients and 767 eyes (patients with last ranibizumab injection 25-36 months after first ranibizumab injection, $22.2 \%$ of analysis population). The remaining 1356 patients were treated for 1 year or less, but were observed for at least 1 year.

Most patients in subgroups A and B were partiallyreimbursed for ranibizumab. In subgroup B specifically, 

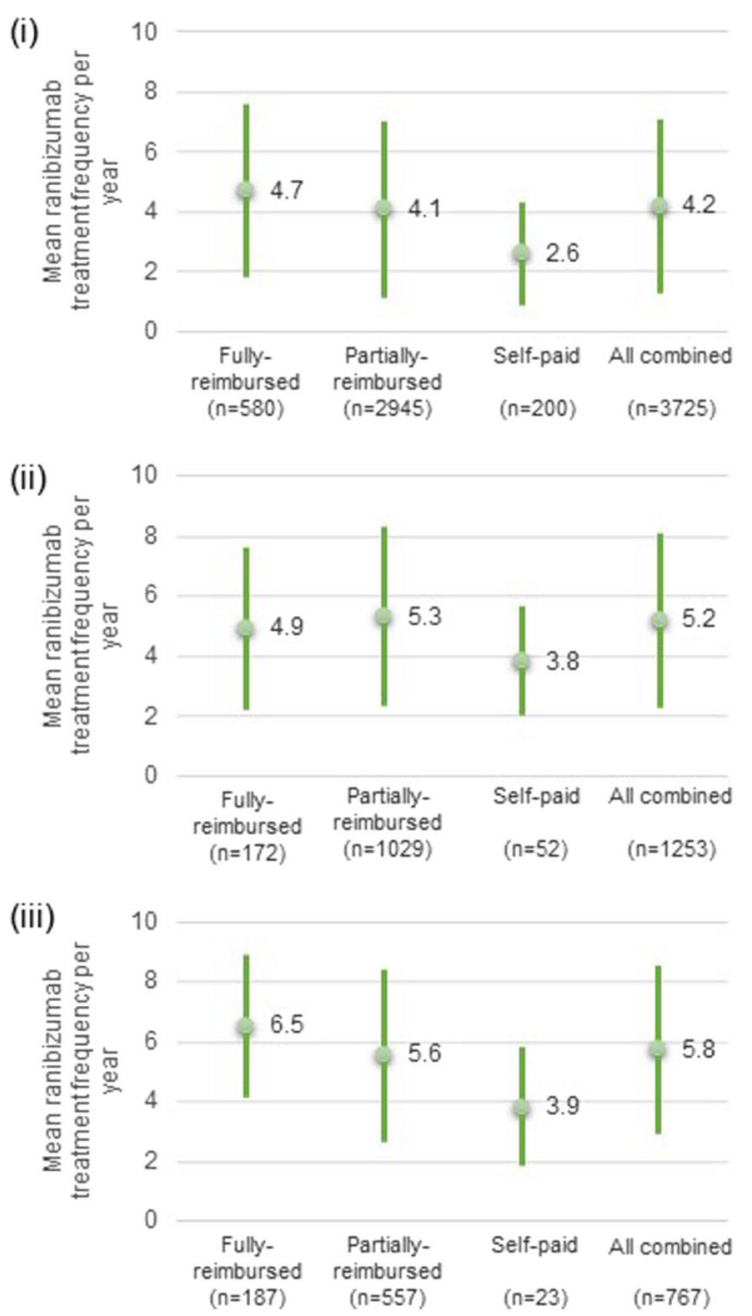

Fig. 1 Mean ranibizumab treatment frequency per year. (i) Overall population. (ii) Subgroup A: patients with a last recorded ranibizumab injection occurring between 13 and 24 months after the first recorded ranibizumab injection. (iii) Subgroup B: patients with a last recorded ranibizumab injection occurring between 25 and 36 months after the first recorded injection (i)
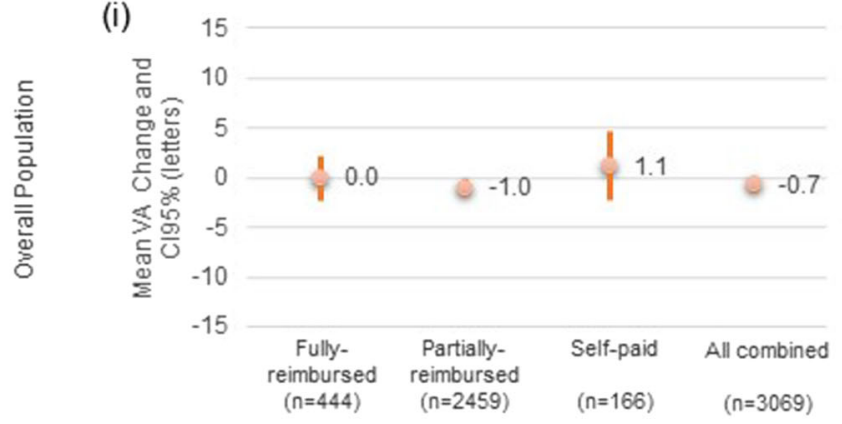

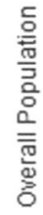

(ii)

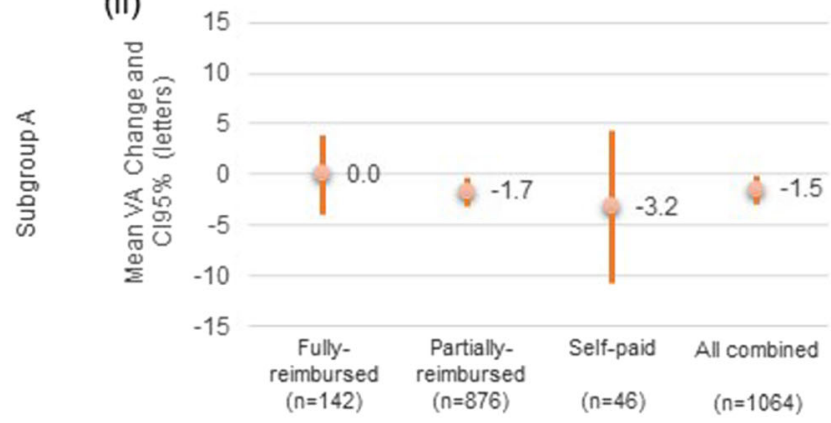

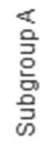

(iii)

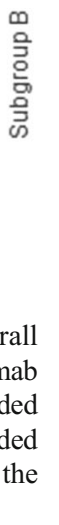

Fig. 2 Mean visual acuity change. Note: visual acuity (VA) change was assessed on 3069 eyes in the overall population, on 1064 eyes in the subgroup A, and on 555 eyes in the subgroup B. (i) Overall population. (ii) Subgroup A: patients with a last recorded ranibizumab injection occurring between 13 and 24 months after the first recorded ranibizumab injection. (iii) Subgroup B: patients with a last recorded ranibizumab injection occurring between 25 and 36 months after the first recorded injection

Table 4 Clinical monitoring in the overall eye-population and in the subgroups (A and B)

\begin{tabular}{|c|c|c|c|c|}
\hline \multirow[t]{2}{*}{ Clinical monitoring } & \multicolumn{3}{|c|}{ Ranibizumab medical coverage } & \multirow[t]{2}{*}{ All combined } \\
\hline & Fully-reimbursed & Partially-reimbursed & Self-paid & \\
\hline Overall eye-population, no. & 580 & 2954 & 200 & 3725 \\
\hline Mean clinic visit number [SD] & $6.6[3.43]$ & $6.7[3.58]$ & $6.9[2.91]$ & $6.7[3.53]$ \\
\hline Subgroup $\mathrm{A}^{\mathrm{a}}$ - eye-population, No. & 172 & 1029 & 52 & 1253 \\
\hline Mean clinic visit number [SD] & $7.9[3.91]$ & $7.5[3.84]$ & $7.8[2.36]$ & $7.6[3.81]$ \\
\hline Subgroup $\mathrm{B}^{\mathrm{a}}$ - eye-population, No. & 187 & 557 & 23 & 767 \\
\hline Mean clinic visit number [SD] & $5.2[2.31]$ & $6.4[3.17]$ & $7.9[3.23]$ & $6.1[3.04]$ \\
\hline
\end{tabular}

${ }^{a}$ Subgroup A: patients with a last recorded ranibizumab injection occurring between 13 and 24 months after the first recorded ranibizumab injection. Subgroup B: patients with a last recorded ranibizumab injection occurring between 25 and 36 months after the first recorded injection

$S D$, standard deviation 
(i)

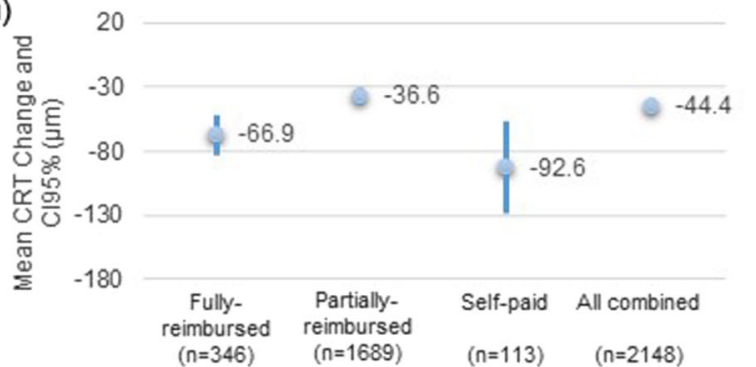

(ii)

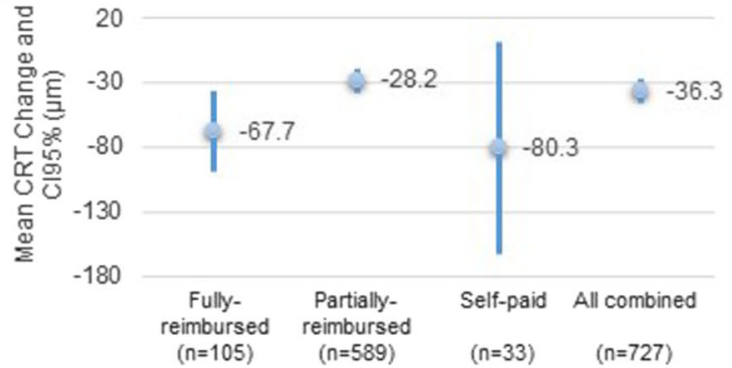

(iii)

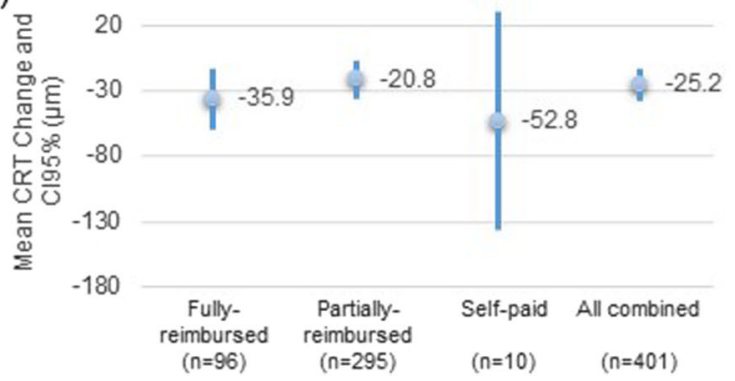

Fig. 3 Mean central retinal thickness change. Note: Central retinal thickness (CRT) change was assessed on 2148 eyes in the overall population, 727 eyes in the subgroup A, and on 401 eyes in the subgroup B. (i) Overall population. (ii) Subgroup A: patients with a last recorded ranibizumab injection occurring between 13 and 24 months after the first recorded ranibizumab injection. (iii) Subgroup B: patients with a last recorded ranibizumab injection occurring between 25 and 36 months after the first recorded injection

$24.2 \%(n=174)$ of patients were fully-reimbursed, and $2.9 \%$ $(n=21)$ were self-paid.

Prior to the ranibizumab initiation, $12.8 \%(n=160)$ of patients received nAMD treatment in subgroup A, compared to $23.3 \%(n=179)$ in subgroup B. Previous nAMD treatment (mainly another anti-VEGF or PDT) was most common in the self-paid group.

Compared to the overall eye-population, subgroup A received 1 additional injection per year on average, while subgroup $\mathrm{B}$ received 1.6 additional injections per year. Patients in the self-paid group had the lowest mean yearly injection frequency in both subgroups (approximately 4 injections per year) (Fig. 1). Patients in subgroup A were more frequently monitored (1.5 additional visits per year on average) than patients in subgroup B (Table 4).
The mean VA change from baseline was lower than 5 letters in subgroups A and B $(-1.5[ \pm 21.96]$ and $-2.5[ \pm 21.65]$ letters respectively). Similar mean VA changes (no change or loss lower than 5 letters) were observed across all reimbursement categories (Fig. 2). A CRT decrease was observed in both subgroups and within all reimbursement categories; mean CRT change was $-36.3( \pm 136.54)$ and -25.2 $( \pm 124.44) \mu \mathrm{m}$ in subgroups $\mathrm{A}$ and $\mathrm{B}$ respectively (Fig. 3). The highest CRT decrease was observed in the self-paid category for both subgroups $(-80.3[ \pm 231.20]$ and -52.8 $[ \pm 117.25] \mu \mathrm{m}$ in subgroups A and B respectively).

\section{Discussion}

This study, based on medical records, evaluated ranibizumab treatment, clinical monitoring frequencies, and visual outcomes of patients treated for nAMD in real-world settings in the Asia-Pacific region, the Middle East, and North Africa. Patients were categorized by three ranibizumab reimbursement scenarios (fully-reimbursed, partially-reimbursed, or self-paid). The partially-reimbursed group was the most prevalent reimbursement category in this study, with 2521 patients, corresponding to 2954 eyes. Markedly fewer patients were fully-reimbursed or self-paid for ranibizumab.

During the study period, patients were monitored approximately 7 times per year on average, irrespective of reimbursement category and ranibizumab dosing regimen. This was aligned with the findings from the AURA study (a retrospective observational study of treatment-naïve ranibizumab nAMD patients conducted in Europe, Canada and Venezuela) where patients had 7.5 monitoring visits and 9.8 clinic visits on average over 2 years of observation [17]. At the time of the study period, PRN and T\&E were most commonly used in routine clinical practice, as such, the study population was probably receiving a mix of the two regimens. Oubraham et al. studied ranibizumab treatment-naïve patients under these two regimens during a 1-year period in which the number of monitoring visits was similar across those regimens, similar to the UNCOVER study. However, compared to the UNCOVER study population, the PRN group received approximately 1 more ranibizumab injection per year, the T\&E group received approximately 4 more injections per year, and patients were monitored more frequently [18]. In a recent meta-analysis of 20 observational studies on ranibizumab treatment for nAMD mostly conducted in single countries in Europe, patients were receiving 1 more injection on average at 1 year compared to the UNCOVER population that was observed during a longer period [19]. The self-paid patients were treated less frequently on average ( 1 injection every 5 months) than patients who received any reimbursement (1 injection every 3 months), suggesting that reimbursement scenario can impact the number of injections received. In the AURA study, where 
Table 5 Safety outcomes: eye disorders

\begin{tabular}{lcccc}
\hline Adverse events & Ranibizumab medical coverage & & $\begin{array}{l}\text { All combined } \\
(n=3445)\end{array}$ \\
\cline { 2 - 4 } & $\begin{array}{l}\text { Fully-reimbursed } \\
(n=568)\end{array}$ & $\begin{array}{l}\text { Partially-reimbursed } \\
(n=2666)\end{array}$ & $\begin{array}{c}\text { Self-paid } \\
(n=210)\end{array}$ & \\
\hline Eye disorders no. $(\%)$ & $55(9.7 \%)$ & $192(7.2 \%)$ & $46(21.9 \%)$ & $293(8.5 \%)$ \\
Cataract & $3(0.5 \%)$ & $46(1.7 \%)$ & $5(2.4 \%)$ & $54(1.6 \%)$ \\
Conjunctival hemorrhage & $8(1.4 \%)$ & $19(0.7 \%)$ & $16(7.6 \%)$ & $43(1.2 \%)$ \\
Retinal detachment & $4(0.7 \%)$ & $7(0.3 \%)$ & $13(6.2 \%)$ & $24(0.7 \%)$ \\
Dry eye & $6(1.1 \%)$ & $14(0.5 \%)$ & $0(0.0 \%)$ & $20(0.6 \%)$ \\
Detachment of retinal & $2(0.4 \%)$ & $8(0.3 \%)$ & $4(1.9 \%)$ & $14(0.4 \%)$ \\
$\quad$ pigment epithelium & $2(0.4 \%)$ & $3(0.1 \%)$ & $8(3.8 \%)$ & $13(0.4 \%)$ \\
Vitreous hemorrhage & $5(0.9 \%)$ & $1(0.0 \%)$ & $6(2.9 \%)$ & $12(0.3 \%)$ \\
Retinal hemorrhage & $2(0.4 \%)$ & $4(0.2 \%)$ & $4(1.9 \%)$ & $10(0.3 \%)$ \\
Eye hemorrhage & $1(0.2 \%)$ & $5(0.2 \%)$ & $2(1.0 \%)$ & $8(0.2 \%)$ \\
Conjunctivitis & $1(0.2 \%)$ & $3(0.1 \%)$ & $4(1.9 \%)$ & $8(0.2 \%)$ \\
Trichiasis & $0(0.0 \%)$ & $3(0.1 \%)$ & $2(1.0 \%)$ & $5(0.1 \%)$ \\
Cystoid macular edema & $2(0.4 \%)$ & $1(0.0 \%)$ & $2(1.0 \%)$ & $5(0.1 \%)$ \\
Eye discharge & $2(0.4 \%)$ & $1(0.0 \%)$ & $2(1.0 \%)$ & $5(0.1 \%)$ \\
Macular scar & $0(0.0 \%)$ & $3(0.1 \%)$ & $2(1.0 \%)$ & $5(0.1 \%)$ \\
Polypoidal choroidal & $1(0.2 \%)$ & $0(0.0 \%)$ & $2(1.0 \%)$ & $3(0.1 \%)$ \\
$\quad$ vasculopathy & $1(0.2 \%)$ & $0(0.0 \%)$ & $2(1.0 \%)$ & $3(0.1 \%)$ \\
Choroidal neovascularization & $0(0.0 \%)$ & $1(0.0 \%)$ & $2(1.0 \%)$ & $3(0.1 \%)$ \\
Retinal depigmentation & & & & \\
Retinal scar & & & & \\
\hline
\end{tabular}

almost the entire study population had a health insurance (93\%) and got reimbursed for ranibizumab injections (95\%), patients had received 5.4 injections on average at 1 year [17]. These findings correlate with the higher number of injections observed in the fully-reimbursed category in UNCOVER population.

The ranibizumab treatment frequency observed in the subgroups of patients with a longer treatment course (i.e., patients having more than 1-year treatment) echoes the findings of a study by Rayess et al. in which treatment-naïve patients starting T\&E, ranibizumab, or bevacizumab received on average 5.7 and 5.8 injections in the second and third years of treatment [20].

In the present study, VA was maintained on average across all reimbursement categories with a relatively low ranibizumab dose regimen (every trimester on average) compared to monthly administration. Similarly, the meta-analysis which encompassed 11 among 20 observational studies with treatment-naïve patients estimated a change in VA at 1 year of +1.95 letters, weighted on the number of eyes treated [19]. In the AURA study, vision was maintained at 2 years in $67 \%$ of patients who were treatment-naïve [17]. Recent clinical trials
Table 6 Concomitant nAMD therapy

\begin{tabular}{|c|c|c|c|c|}
\hline \multirow[t]{2}{*}{ Concomitant therapy } & \multicolumn{3}{|c|}{ Ranibizumab medical coverage } & \multirow{2}{*}{$\begin{array}{l}\text { All combined } \\
(n=3725)\end{array}$} \\
\hline & $\begin{array}{l}\text { Fully-reimbursed } \\
(n=580)\end{array}$ & $\begin{array}{l}\text { Partially-reimbursed } \\
(n=2945)\end{array}$ & $\begin{array}{l}\text { Self-paid } \\
(n=200)\end{array}$ & \\
\hline Eyes treated, no. $(\%)$ & $88(15.2 \%)$ & $164(5.6 \%)$ & $81(40.5 \%)$ & $333(8.9 \%)$ \\
\hline \multicolumn{5}{|l|}{ Therapy, no. (\%) } \\
\hline $\begin{array}{l}\text { Verteporfin photodynamic } \\
\text { therapy }\end{array}$ & $61(10.5 \%)$ & $67(2.3 \%)$ & $66(33.0 \%)$ & $194(5.2 \%)$ \\
\hline Laser & $12(2.1 \%)$ & $30(1.0 \%)$ & $5(2.5 \%)$ & $47(1.3 \%)$ \\
\hline Steroid & $6(1.0 \%)$ & $29(1.0 \%)$ & 0 & $35(0.9 \%)$ \\
\hline Surgery & $2(0.3 \%)$ & $21(0.7 \%)$ & $6(3.0 \%)$ & $29(0.8 \%)$ \\
\hline Other & $10(1.7 \%)$ & $30(1.0 \%)$ & $6(3.0 \%)$ & $46(1.2 \%)$ \\
\hline
\end{tabular}

$n A M D$, neovascular age-related macular degeneration 
Table 7 Switch to another antiVEGF

\begin{tabular}{lllll}
\hline Therapy switch & \multicolumn{2}{l}{ Ranibizumab medical coverage } & \\
\cline { 2 - 4 } & $\begin{array}{l}\text { Fully-reimbursed } \\
(n=580)\end{array}$ & $\begin{array}{l}\text { Partially-reimbursed } \\
(n=2945)\end{array}$ & $\begin{array}{l}\text { Self-paid } \\
(n=200)\end{array}$ & $\begin{array}{l}\text { All combined } \\
(n=3725)\end{array}$ \\
\hline Eyes switching, no. (\%) & $36(6.2 \%)$ & $294(10.0 \%)$ & $11(5.5 \%)$ & $341(9.2 \%)$ \\
Reason for switch, no. (\%) & & & & \\
Cost & $6(1.0 \%)$ & $125(4.2 \%)$ & $4(2.0 \%)$ & $135(3.6 \%)$ \\
Unknown & $8(1.4 \%)$ & $97(3.3 \%)$ & $3(1.5 \%)$ & $108(2.9 \%)$ \\
Efficacy & $18(3.1 \%)$ & $58(2.0 \%)$ & $1(0.5 \%)$ & $77(2.1 \%)$ \\
Patient preference & $2(0.3 \%)$ & $13(0.4 \%)$ & $6(3.0 \%)$ & $21(0.6 \%)$ \\
Other & $1(0.2 \%)$ & $11(0.4 \%)$ & 0 & $12(0.3 \%)$ \\
Safety/tolerability & 0 & $3(0.1 \%)$ & 0 & $3(0.1 \%)$ \\
Clinical trial participation & $1(0.2 \%)$ & $1(0.0 \%)$ & 0 & $2(0.1 \%)$ \\
Drug accessibility & 0 & $2(0.1 \%)$ & 0 & $2(0.1 \%)$ \\
$\quad$ (other than cost-related) & & & & $250(6.7 \%)$ \\
Therapy taken, no. (\%) & $17(2.9 \%)$ & $224(7.6 \%)$ & $9(4.5 \%)$ & $91(2.4 \%)$ \\
Bevacizumab & $19(3.3 \%)$ & $70(2.4 \%)$ & $2(1.0 \%)$ & \\
Aflibercept & & &
\end{tabular}

Anti-VEGF, anti-vascular endothelial growth factor showed that vision gains were maintained after 2 years in treatment-naïve populations under controlled PRN regimens $[16,21,22]$. Nonetheless, the UNCOVER study population encompassed both treatment-naïve and treatment-experienced patients, where treatment-naïve patients might be more likely to gain vision than treatment-experienced patients, who were more inclined to be in the maintenance phase. In addition, the variation of VA change results was greater (almost 10 letters) in our study compared to those published in clinical trials. A study conducted in Germany showed initial VA improvement that later declined after 4 months of ranibizumab treatment and tended toward baseline or lower in a PRN-treated population (having tour or more injections during the 12-month maintenance phase) [23].

These results were similar to the findings of the UNCOVER study, showing a weak correlation between the VA change and the frequency of ranibizumab injections.

The prognostic effects of selected variables on VA were also studied in the AURA population [24]. Similarly to the findings of the multivariate model in UNCOVER, the number of ranibizumab injections suggested to have a positive effect on VA.

The results observed for the two subgroups, being treated at least 1 or 2 years during the observation period, were consistent with those observed in the overall population. Interestingly, despite receiving injections more frequently, they lost slightly more letters on average than the overall population and showed greater variability. This can be explained by the size of the subgroups representing one-third and onefifth of the overall eye-population assessed for the subgroups being treated at least 1 year and at least 2 years respectively.
Self-paid patients, who were mostly Asian, had the highest baseline CRT and experienced the greatest CRT decrease from baseline. They presented with more eye comorbidities than those in the two other reimbursement categories, notably PCV. Additionally, self-paid patients who had less than 1year observation and thus, were ineligible for the study, may have been less likely to receive routine monitoring. Therefore, their visual outcomes may be different than those observed in the study.

Strengths of this study include the identification of a large, multinational, heterogeneous cohort of patients treated with ranibizumab injections, allowing for a description of ranibizumab treatment frequency and clinical outcomes across different reimbursement scenarios. A limitation inherent to the design of this study is the limited availability and completeness of data in the patient medical records, notably information on AEs. Therefore, AE frequency could have been underestimated.

\section{Conclusion}

This study was the first of its kind to assess the effect of treatment reimbursement on ranibizumab use and treatment outcomes in routine clinical practice in a large heterogeneous population of ranibizumab-treated patients from the AsiaPacific region, the Middle East, and North Africa. Patients were monitored at the same frequency irrespective of ranibizumab reimbursement status; however, more frequent ranibizumab treatment was observed in the fully-reimbursed and partially-reimbursed groups compared to the self-paid 
group. This may indicate that reimbursement scenario can impact the frequency of ranibizumab injections. No gain in VA was observed in the study population; this could be related to the relatively low ranibizumab injection frequencies observed in our study compared to standard regimens. Nevertheless, patients in all reimbursement scenarios attained vision stability on average, indicating control of disease activity.

Acknowledgements This study was sponsored by Novartis Pharma AG, Basel, Switzerland, and its respective affiliates. A contract research organization, IQVIA (formerly Quintiles), was responsible for the conduct of the study, data management, quality review, statistical analysis, report, and scientific communications writing. Medical writing assistance to the authors was provided by Coralie Lecomte, PharmD MSc and Corey Joseph, MPH, from IQVIA. Neither honoraria nor payments were made for authorship.

Author statement All authors participated in the development and writing of the manuscript and take full responsibility for the content of the article.

N.A. was working for Novartis Pharma AG, Basel, Switzerland at the time of the study.

Meeting presentation The UNCOVER study results were presented at Asia-Pacific Vitreo-Retina Society 2015 Congress held in Sydney, Australia as posters, and at the Retinal Society 2015 Annual Meeting held in Paris, France as oral communication.

Compliance with ethical standards All procedures performed in studies involving human participants were in accordance with the ethical standards of the institutional and/or national research committee and with the 1964 Helsinki Declaration and its later amendments or comparable ethical standards.

Conflict of interest The authors acknowledge principal investigators for multiple studies (B.E., T.Y.Y.L., N.F.N., B.V., and H.G.Y.) and acknowledge fees from Novartis for conducting the study.

B.E.'s institution has received grants for board membership, consultancy, and payment for lectures including service on speakers from Novartis Pharma AG, Bayer, Allergan, Alcon, Thea, B\&L, Sanofi, Servier, Ophtotech, Roche, and Santen. T.Y.Y.L. and H.G.Y. have received fees from Allergan, Bayer, Novartis Pharma AG. B.V. has received fees and non-financial support from Novartis Pharma AG and Alcon.

Ethical approval The study protocol was approved by ethics committees/institutional review boards. For this type of historical cohort study based on medical records formal consent was not always required.

Open Access This article is distributed under the terms of the Creative Commons Attribution 4.0 International License (http:// creativecommons.org/licenses/by/4.0/), which permits unrestricted use, distribution, and reproduction in any medium, provided you give appropriate credit to the original author(s) and the source, provide a link to the Creative Commons license, and indicate if changes were made.

\section{References}

1. Vingerling JR, Dielemans I, Hofman A, Grobbee DE, Hijmering M, Kramer CF, de Jong PT (1995) The prevalence of age-related maculopathy in the Rotterdam Study. Ophthalmology 102(2):205-210
2. Bressler NM (1995) Submacular surgery. Are randomized trials necessary? Arch Ophthalmol 113(12):1557-1560. https://doi.org/ 10.1001/archopht.1995.01100120087016

3. Klein R, Klein BE, Jensen SC, Meuer SM (1997) The five-year incidence and progression of age-related maculopathy: the Beaver Dam Eye Study. Ophthalmology 104(1):7-21

4. Kawasaki R, Yasuda M, Song SJ, Chen SJ, Jonas JB, Wang JJ, Mitchell P, Wong TY (2010) The prevalence of age-related macular degeneration in Asians: a systematic review and meta-analysis. Ophthalmology 117(5):921-927. https://doi.org/10.1016/j.ophtha. 2009.10.007

5. Wong WL, Su X, Li X, Cheung CM, Klein R, Cheng CY, Wong TY (2014) Global prevalence of age-related macular degeneration and disease burden projection for 2020 and 2040: a systematic review and meta-analysis. Lancet Glob Health 2(2):e106-e116. https://doi. org/10.1016/S2214-109X(13)70145-1

6. Koh AH, Expert PCVP, Chen LJ, Chen SJ, Chen Y, Giridhar A, Iida T, Kim H, Yuk Yau Lai T, Lee WK, Li X, Han Lim T, Ruamviboonsuk P, Sharma T, Tang S, Yuzawa M (2013) Polypoidal choroidal vasculopathy: evidence-based guidelines for clinical diagnosis and treatment. Retina 33(4):686-716. https://doi.org/10.1097/IAE. 0b013e3182852446

7. Hatz K, Prunte C (2014) Polypoidal choroidal vasculopathy in Caucasian patients with presumed neovascular age-related macular degeneration and poor ranibizumab response. $\mathrm{Br} \mathrm{J}$ Ophthalmol 98(2):188-194. https://doi.org/10.1136/bjophthalmol-2013303444

8. Brown DM, Kaiser PK, Michels M, Soubrane G, Heier JS, Kim RY, Sy JP, Schneider S, ANCHOR Study Group (2006) Ranibizumab versus verteporfin for neovascular age-related macular degeneration. N Engl J Med 355(14):1432-1444. https://doi.org/10.1056/ NEJMoa062655

9. Rosenfeld PJ, Brown DM, Heier JS, Boyer DS, Kaiser PK, Chung CY, Kim RY, MARINA Study Group (2006) Ranibizumab for neovascular age-related macular degeneration. N Engl J Med 355(14):1419-1431. https://doi.org/10.1056/NEJMoa054481

10. Holz FG, Bandello F, Gillies M, Mitchell P, Osborne A, Sheidow T, Souied E, Figueroa MS, LUMINOUS Steering Committee (2013) Safety of ranibizumab in routine clinical practice: 1-year retrospective pooled analysis of four European neovascular AMD registries within the LUMINOUS programme. Br J Ophthalmol 97(9):11611167. https://doi.org/10.1136/bjophthalmol-2013-303232

11. Gupta B, Adewoyin T, Patel SK, Sivaprasad S (2011) Comparison of two intravitreal ranibizumab treatment schedules for neovascular age-related macular degeneration. Br J Ophthalmol 95(3):386-390. https://doi.org/10.1136/bjo.2010.179499

12. Toalster N, Russell M, Ng P (2013) A 12-month prospective trial of inject and extend regimen for ranibizumab treatment of age-related macular degeneration. Retina 33(7):1351-1358. https://doi.org/10. 1097/IAE.0b013e3182831265

13. Abedi F, Wickremasinghe S, Islam AF, Inglis KM, Guymer RH (2014) Anti-VEGF treatment in neovascular age-related macular degeneration: a treat-and-extend protocol over 2 years. Retina 34(8):1531-1538. https://doi.org/10.1097/IAE.0000000000000134

14. Berg K, Pedersen TR, Sandvik L, Bragadóttir R (2015) Comparison of ranibizumab and bevacizumab for neovascular age-related macular degeneration according to LUCAS treat-and-extend protocol. Ophthalmology 122(1):146-152. https://doi.org/10.1016/j.ophtha. 2014.07.041

15. Busbee BG, Ho AC, Brown DM, Heier JS, Suñer IJ, Li Z, Rubio RG, Lai P, HARBOR Study Group (2013) Twelve-month efficacy and safety of $0.5 \mathrm{mg}$ or $2.0 \mathrm{mg}$ ranibizumab in patients with subfoveal neovascular age-related macular degeneration. Ophthalmology 120(5):1046-1056. https://doi.org/10.1016/j. ophtha.2012.10.014 
16. Ho AC, Busbee BG, Regillo CD, Wieland MR, Van Everen SA, Li Z, Rubio RG, Lai P, HARBOR Study Group (2014) Twenty-four-month efficacy and safety of $0.5 \mathrm{mg}$ or $2.0 \mathrm{mg}$ ranibizumab in patients with subfoveal neovascular age-related macular degeneration. Ophthalmology 121(11):2181-2192. https://doi.org/10.1016/j. ophtha.2014.05.009

17. Holz FG, Tadayoni R, Beatty S, Berger AR, Cereda MG, Hykin P, Staurenghi G, Wittrup-Jensen K, Nilsson J, Kim K, Sivaprasad S (2016) Determinants of visual acuity outcomes in eyes with neovascular AMD treated with anti-VEGF agents: an instrumental variable analysis of the AURA study. Eye 30(8):1063-1071. https:// doi.org/10.1038/eye.2016.90

18. Oubraham H, Cohen SY, Samimi S, Marotte D, Bouzaher I, Bonicel P, Fajnkuchen F, Tadayoni R (2011) Inject and extend dosing versus dosing as needed: a comparative retrospective study of ranibizumab in exudative age-related macular degeneration. Retina 31(1):26-30. https://doi.org/10.1097/IAE. 0b013e3181de5609

19. Chong V (2016) Ranibizumab for the treatment of wet AMD: a summary of real-world studies. Eye 30(11):1526. https://doi.org/ 10.1038/eye.2016.202

20. Rayess N, Houston SK 3rd, Gupta OP, Ho AC, Regillo CD (2015) Treatment outcomes after 3 years in neovascular age-related macular degeneration using a treat-and-extend regimen. Am J Ophthalmol 159(1):3-8 e1. https://doi.org/10.1016/j.ajo.2014.09.011
21. Chakravarthy U, Harding SP, Rogers CA, Downes SM, Lotery AJ, Culliford LA, Reeves BC, study investigators IVAN (2013) Alternative treatments to inhibit VEGF in age-related choroidal neovascularisation: 2-year findings of the IVAN randomised controlled trial. Lancet 382(9900):1258-1267. https://doi.org/10.1016/ S0140-6736(13)61501-9

22. Ying GS, Kim BJ, Maguire MG, Huang J, Daniel E, Jaffe GJ, Grunwald JE, Blinder KJ, Flaxel CJ, Rahhal F, Regillo C, Martin DF, CATT Research Group (2014) Sustained visual acuity loss in the comparison of age-related macular degeneration treatments trials. JAMA Ophthalmology 132(8):915-921. https://doi.org/10. 1001/jamaophthalmol.2014.1019

23. Wolf A, Kampik A (2014) Efficacy of treatment with ranibizumab in patients with wet age-related macular degeneration in routine clinical care: data from the COMPASS health services research. Graefes Arch Clin Exp Ophthalmol 252(4):647-655. https://doi. org/10.1007/s00417-013-2562-6

24. Holz FG, Tadayoni R, Beatty S, Berger A, Cereda MG, Hykin P, Staurenghi G, Wittrup-Jensen K, Altemark A, Nilsson J, Kim K, Sivaprasad S (2016) Key drivers of visual acuity gains in neovascular age-related macular degeneration in real life: findings from the AURA study. Br J Ophthalmol 100(12):1623-1628. https://doi.org/10.1136/bjophthalmol-2015-308166 